\title{
PENGARUH CARA PENGERINGAN SIMPLISIA TERHADAP KADAR FENOLIK DAN AKTIVITAS TABIR SURYA EKSTRAK ETANOL 70\% DAUN CINCAU HIJAU (Cyclea barbata Miers.)
}

\author{
Lisa Rusmawati ${ }^{1)}$, Landyyun Rahmawan Sjahid ${ }^{2)}$, Sofia Fatmawati ${ }^{3{ }^{3}}$ *) \\ ${ }^{1}$ Fakultas Farmasi dan Sains, Universitas Muhamamdiyah Prof Dr Hamka \\ ${ }^{2}$ Unit Biologi Farmasi, Fakultas Farmasi dan Sains, Universitas Muhamamdiyah Prof Dr Hamka \\ ${ }^{3}$ Unit Kimia Farmasi, Fakultas Farmasi dan Sains, Universitas Muhamamdiyah Prof Dr Hamka \\ *email: fatmawatisofia@gmail.com
}

\begin{abstract}
Extract cincau leaves green according to previous studies have the value of the antioxidant IC50 49,45 $\pm 0,64 \mu \mathrm{g} / \mathrm{mL}$. According to researchers the phenol formerly produced through a method of drying oven with higher than the drying with sunlight and dried use wind. The research aims to understand the influence of means drying simplisia against phenolic levels total and the activity of a natural sunscreen on extract ethanol $70 \%$ cincau leaves green (Cyclea barbata Miers). Drying simplisia in research is divided into three which is drying with the dry wind, the sun, and an oven. Green leaves cincau simplisia extracted by using the method maceration. Testing the phenolic committed using the folin ciocalteu method. The determination is based on the SPF value Mansur. The results of the value of phenolic or on the program have managed to extract by the difference means drying simplisia dry wind, the rays of the sun and an oven respectively namely 32,7089; 46,2500 and 59,5500 $\mathrm{mgGAE} / \mathrm{g}$. The SPF value obtained from each extract with different methods of drying simplisia showed significant differences in various concentration test.
\end{abstract}

Keywords: drying, cincau, leaves, phenolic, sunscreen

\section{PENDAHULUAN}

Matahari memancarkan sinar yang mengandung radiasi ultra violet (UV) yang tidak dapat dilihat dan dirasakan secara langsung oleh diri manusia. Pada dasarnya, sinar ultra violet dari matahari memiliki manfaat yang baik, salah satunya adalah untuk pembentukan kolekalsiferol (Vitamin D3). Selain itu, radiasi sinar UV dalam waktu yang cukup dan rutin seringkali digunakan untuk terapi penyakit tuberkulosis, psoriasis, dan vitiligo (Cefali dkk, 2016).

Radiasi yang berlebihan dapat mengakibatkan efek merugikan pada manusia. Radiasi sinar UV-B yang memiliki panjang gelombang 290-320 nm dapat menembus dengan baik stratum corneum dan epidermis yang cukup parah dan menyebabkan iritasi pada kulit sehingga disebut daerah eritema. Radiasi sinar UV-A memiliki panjang gelombang 320-400 nm dapat menyebabkan warna cokelat (tanning) pada kulit tanpa terjadi inflamasi sehingga disebut daerah pigmentasi. Meskipun sinar UV-A memiliki energi yang lebih rendah daripada sinar UV-B, tetapi kenyataannya keduanya dapat menembus lebih jauh ke dalam hipodermis, menyebabkan elastosis (kekurangan dengan struktural dan elastisitas kulit) dan kerusakan kulit lainnya, UV-B berpotensi mengarah ke kanker kulit (Setiawan, 2010).

Kulit adalah organ tubuh terluar dan terbesar oleh karena itu paling cenderung secara langsung terpapar sinar 
matahari. Tahun belakangan ini, akibat dari radiasi ultraviolet dihubungkan dengan penyakit dan kelainan pada pertumbuhan. Ketika kulit terpapar radiasi ultraviolet dalam waktu yang lama, hal tersebut dapat meningkatkan radikal bebas. Radikal bebas dapat memacu terjadinya kanker kulit (Afaq \& Mukhtar, 2001).

Kerusakan yang disebabkan oleh radikal bebas dapat dicegah atau dihambat oleh suatu senyawa antioksidan. Antioksidan merupakan senyawa yang dapat menghentikan reaksi berantai dari radikal bebas di dalam tubuh sehingga selsel tubuh dapat terhindar dari kerusakan akibat reaksi dari radikal bebas (Hernani, 2005), selain itu antioksidan dapat menyumbangkan elektronnya kepada radikal bebas dan menstabilkan radikal tersebut sehingga menjadi tidak reaktif lagi (Suhartono, 2002).

Salah satu sumber antioksidan alami yang terdapat dalam tumbuhan adalah senyawa fenolik. Diantara sekian banyak senyawa fenolik tumbuhan yang diketahui, golongan flavonoid merupakan golongan terbanyak yang bersifat sebagai antioksidan. Kemampuan flavonoid untuk menghambat radikal bebas terjadi karena adanya gugus hidroksi fenolik dalam struktur molekulnya (Kate, 2014).

Ekstrak daun cincau hijau (Cyclea barbata Miers.) diketahui mengandung alkaloid, flavonoid, steroid/triterpenoid, tannin, saponin dan kumarin serta ekstrak daun cincau hijau juga memiliki antioksidan yang tinggi dengan nilai $\mathrm{IC}_{50}$ $49,45 \pm 0,64 \mu \mathrm{g} / \mathrm{ml}$ dan nilai total flavonoid sebesar 9,93 $\pm 0,2 \%$ (Farida dkk, 2015). Menurut Muller (2006), pengeringan simplisia dengan oven dianggap lebih menguntungkan karena akan terjadi pengurangan kadar air dalam jumlah besar dalam waktu yang singkat.

Berdasarkan uraian tersebut, daun cincau hijau diketahui memiliki senyawa fenolik dan berpotensi sebagai tabir surya. Oleh karena itu, perlu dilakukan penelitian untuk mengetahui pengaruh perbedaan cara pengeringan simplisia terhadap kadar fenolik total serta aktivitas tabir surya pada ekstrak etanol $70 \%$ daun cincau hijau.

\section{METODE PENELITIAN}

Alat

Pisau, toples kaca, pipa kapiler (Marienfeld), batang pengaduk, pipet tetes, mikropipet (DUMO), beaker glass (pyrex IWAKI), wadah cokelat, labu ukur (pyrex IWAKI), tabung reaksi (pyrex IWAKI), kaca arloji, botol timbang (IWAKI), krus, ayakan mesh 40, kertas saring, spatel, gelas ukur (Pyrex IWAKI), neraca analitik (OHAUS), digital termostatic water bath (Thomas scientific), oven (Mammert Un 110), hot plate (AKEBONNO), alumunium foil, UV Lamp (CAMAG), kuvet, kertas saring, vakum rotary evaporator (EYELA), moisture balance (Mettler toledo), spektrofotometer UV-Vis UV1900 (Shimadzu).

\section{Bahan}

Daun cincau hijau (C. barbata Miers.), etanol 70\%, etanol p.a. (SmartLab), besi (III) klorida 1\% (Merck KgaA), aquadest, $\mathrm{HCl}$, DCM, Metanol, pereaksi Dragendroff, Mayer, Bouchardat, Wagner, amonia, asam sulfat $5 \%$, asam nitrat $25 \%$, potasium asetat natrium hidroksida $5 \%$, asam klorida $5 \%$, besi (III) klorida $1 \%$ (Merck KgaA), eter, asam asetat anhidrat (Tedia), Magnesium Powder (Merck KgaA), Asam Galat (Sigma-Aldrich), Folin Ciocalteu (Merck KgaA), Na2Co3 dan lain-lain.

\section{Pembuatan ekstrak}

Sejumlah $600 \mathrm{~g}$ serbuk simplisia daun cincau hijau (C.barbata Miers.) diekstraksi menggunakan metode maserasi dengan pelarut etanol $70 \%$ dengan remaserasi sebanyak 6 kali. Selanjutnya dilakukan filtrasi dan diuapkan menggunakan rotary vacum evaporator. Ekstrak disimpan dalam desikator dan digunakan untuk percobaan selanjutnya 
(Farida dkk, 2015). Ekstrak tersebut dihitung rendemennya, diuji organoleptik, kadar air, kadar abu total dan skrining fitokimia.

\section{Penetapan kadar fenolik}

Kadar fenolik total ditetapkan menggunakan metode Folin Ciocalteu dengan sedikit perubahan. Sebanyak $1 \mathrm{~mL}$ larutan ekstrak $1000 \mathrm{ppm}$ dan ditambah 5 $\mathrm{mL}$ reagen Folin-Ciocalteau 10\% (yang telah dilarutkan dalam aqudest) digojog didiamkan selama 8 menit dan ditambah 4 mL larutan $\mathrm{Na} 2 \mathrm{CO} 37,5 \%$ (Siddiqui dkk, 2017). Didiamkan lagi pada range operating time 126 menit pada suhu kamar. Absorbansi larutan ekstrak diukur dengan spekrofotometer UV-Vis pada panjang gelombang absorbansi maksimum $759 \mathrm{~nm}$. Lakukan 3 kali pengulangan sehingga kadar fenol yang diperoleh hasilnya didapat sebagai mgGAE/g ekstrak. Kandungan total fenolik dihitung menggunakan rumus(1) (Siddiqui dkk., 2017):

$\mathrm{C}=\frac{\mathrm{C} 1 \cdot \mathrm{v} \cdot \mathrm{FP}}{\mathrm{m}}$

Keterangan:

$\mathrm{C}=$ Kandungan total fenolik dalam mg/g, dalam GAE (Gallic Acid Equivalent)

$\mathrm{C} 1=$ Konsentrasi asam galat dibentuk dari kurva kalibrasi $(\mathrm{mg} / \mathrm{mL})$

$\mathrm{V}=$ Volume ekstrak $(\mathrm{mL})$

$\mathrm{M} \quad=$ Berat ekstrak $(\mathrm{g})$

\section{Uji tabir surya}

Sebanyak 10 mg ekstrak daun cincau hijau dipindahkan ke labu volumetrik 10,0 mL lalu ad tanda batas dengan etanol lalu disaring untuk memberikan larutan 1000 ppm. Dibuat dengan berbagai konsentrasi yaitu 50 ppm, 100 ppm, 150 ppm dengan masing - masing pelarut. Lalu baca serapan pada panjang gelombang 290 - 320 $\mathrm{nm}$ tiap kenaikan $5 \mathrm{~nm}$ menggunakan spektrofotometri UV-Vis digunakan etanol sebagai blanko (Priyanka dkk, 2018).
Penentuan nilai SPF dilakukan berdasarkan persamaan Mansur (1986)(2):

$\mathrm{SPF}=$

CFx $\sum_{290}^{320} \mathrm{EE}(\lambda) \mathrm{xI}(\lambda) \mathrm{xAbs}(\lambda)$

$\mathrm{CF}=$ Faktor korelasi (10),

$\mathrm{EE}=$ efisiensi eritema radiasi dengan panjang gelombang $\lambda$,

I = spektrum intensitas cahaya,

Abs = absorbansi sampel tabir surya.

Nilai EE x I adalah suatu konstanta yang sudah ditetapkan menurut (Sayre dkk, 1979) pada Tabel 1.

Tabel 1. Nilai EE x I (Sayre dkk, 1979)

\begin{tabular}{cc}
\hline $\begin{array}{c}\text { Panjang gelombang } \\
(\boldsymbol{\lambda} \text { nm })\end{array}$ & Ee x I \\
\hline 290 & 0,0150 \\
295 & 0,0817 \\
300 & 0,2874 \\
305 & 0,3278 \\
310 & 0,1864 \\
315 & 0,0839 \\
320 & 0,0180 \\
Total & 1,000 \\
\hline
\end{tabular}

\section{HASIL DAN PEMBAHASAN}

Hasil rendemen ekstrak etanol $70 \%$ daun cincau hijau yang didapatkan (Tabel 2) menunjukkan bahwa hasil rendemen terbesar diperoleh ekstrak dengan cara pengeringan simplisia sinar matahari. Pengeringan simplisia dengan oven didapatkan rendemen yang sedikit dikarenakan banyaknya ekstrak cair yang tumpah pada saat pengentalan ekstrak sehingga mempengaruhi hasil rendemen yang didapat.

Tabel 2. Hasil rendemen ekstrak

\begin{tabular}{lccc}
\hline $\begin{array}{l}\text { Jenis } \\
\text { pengering } \\
\text {-an } \\
\text { simplisia }\end{array}$ & $\begin{array}{c}\text { Serbuk } \\
\text { simplisia }\end{array}$ & $\begin{array}{c}\text { Ekstrak } \\
\text { kental }\end{array}$ & $\begin{array}{c}\% \\
\text { Rende- } \\
\text { men }\end{array}$ \\
\hline $\begin{array}{l}\text { Kering } \\
\text { angin }\end{array}$ & $200 \mathrm{~g}$ & $22,12 \mathrm{~g}$ & $11,06 \%$ \\
$\begin{array}{l}\text { Sinar } \\
\text { matahari }\end{array}$ & $200 \mathrm{~g}$ & $29,42 \mathrm{~g}$ & $14,71 \%$ \\
Oven & $200 \mathrm{~g}$ & $15,56 \mathrm{~g}$ & $7,78 \%$ \\
\hline
\end{tabular}


Susut Pengeringan bertujuan untuk mengetahui kadar air dan senyawa volatile yang terkandung didalam ekstrak. Kadar air sebaiknya lebih kecil dari 10\%. Apabila kadar air lebih besar dari 10\% akan menyebabkan terjadinya proses enzimatik dan kerusakan oleh mikroba (Manoi, 2006). Hasil susut pengeringan dan kadar abu dapat dilihat pada Tabel 3. Dari semua hasil susut pengeringan yang didapatkan tidak melebih dari $10 \%$ yang berarti masing masing ekstrak memenuhi kriteria standar.

Pengujian Kadar Abu bertujuan untuk mengetahui kadar bahan anorganik atau mineral-mineral yang terdapat dalam ekstrak setelah dilakukan pengabuan. Kadar abu daun cincau hijau menurut Depkes (1989), tidak lebih dari 17\%. Dari semua sampel ekstrak jika dibandingkan dengan yang ada menurut Depkes (1989), hasil yang didapatkan dari masing-masing ekstrak dengan pengaruh cara pengeringan kering angin, sinar matahari dan oven lebih kecil dibandingkan yang terdapat pada literatur. Hal ini dapat dipengaruhi dari tanah, lingkungan tempat tumbuh dan pengaruh lainnya.

Tabel 3. Hasil susut pengeringan dan kadar abu

\begin{tabular}{lcc}
\hline $\begin{array}{l}\text { Jenis Ekstrak } \\
\text { Berdasarkan } \\
\text { Cara } \\
\begin{array}{l}\text { Pengeringan } \\
\text { Simplisia }\end{array}\end{array}$ & $\begin{array}{c}\text { Susut } \\
\text { Pengeringan }\end{array}$ & $\begin{array}{c}\text { Kadar } \\
\text { Abu }\end{array}$ \\
\hline Kering angin & $4,75 \% \pm 0,57$ & $16,09 \%$ \\
& & $\pm 0,10$ \\
Sinar matahari & $4,16 \% \pm 0,17$ & $15,51 \%$ \\
& $3,95 \% \pm 0,16$ & $15,36 \%$ \\
Oven & & $\pm 0,42$ \\
\hline
\end{tabular}

Penapisan fitokimia pada ekstrak daun cincau hijau dilakukan dengan 3 perlakuan berdasarkan perbedaan cara pengeringan simplisia yaitu kering angin, sinar matahari dan oven yang terdapat pada Tabel 4. Dari hasil yang didapatkan disimpulkan bahwa ekstrak daun cincau hijau mengandung senyawa fenol, flavonoid, alkaloid, tanin, saponin dan terpenoid.

Tabel 4. Hasil penapisan ekstrak

\begin{tabular}{|c|c|c|c|}
\hline $\begin{array}{l}\text { Uji } \\
\text { Identifikasi }\end{array}$ & $\begin{array}{l}\text { Kering } \\
\text { Angin }\end{array}$ & $\begin{array}{c}\text { Ekstrak } \\
\text { Sinar } \\
\text { Matahari }\end{array}$ & Oven \\
\hline Fenol & $(+)$ & $(+)$ & $(+)$ \\
\hline Flavonoid & $(+)$ & $(+)$ & $(+)$ \\
\hline Alkaloid: & $(+)$ & $(+)$ & $(+)$ \\
\hline Tanin & $(+)$ & $(+)$ & $(+)$ \\
\hline Saponin & $(+)$ & $(+)$ & $(+)$ \\
\hline Terpenoid & $(+)$ & $(+)$ & $(+)$ \\
\hline Steroid & $(-)$ & $(-)$ & $(-)$ \\
\hline \multicolumn{2}{|c|}{$\begin{array}{l}\text { Keterangan : } \\
(+) \text { Mengandung } \\
\text { teridentifikasi }\end{array}$} & senyawa & \\
\hline
\end{tabular}

Senyawa fenol juga terdeteksi menggunakan metode kromatografi lapis tipis (KLT) dengan fase gerak kloroformetil asetat - toluen (2:6:2). Pengamatan dilakukan pada sinar UV (Ultra Violet) tampak $254 \mathrm{~nm}$ dan $366 \mathrm{~nm}$ (Mahadi dkk, 2018). Pada sinar UV $254 \mathrm{~nm}$ terdapat bercak biru kehitaman namun pada UV $366 \mathrm{~nm}$ tidak ditemukan bercak apapun (Gambar 1). Setelah itu dilakukan penyemprotan lempeng menggunakan $\mathrm{FeCl}_{3}$ yang digunakan untuk mendeteksi senyawa golongan fenol. Nilai $\mathrm{R} f$ yang didapatkan secara berurutan berdasarkan cara pengeringan dengan kering angin, sinar matahari dan oven yaitu 0,$8 ; 0,8769$; 0,8923 . 


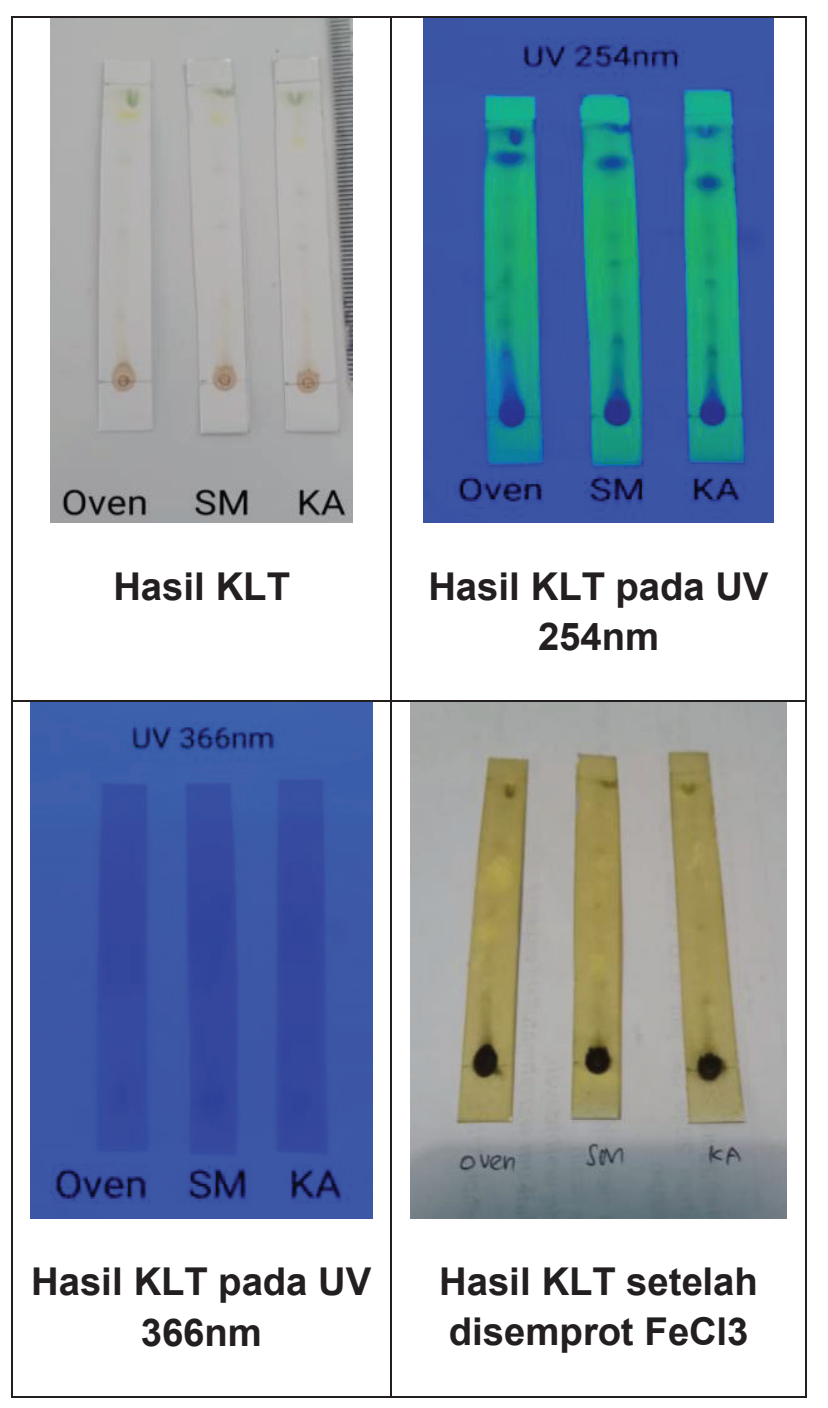

Gambar 1. Hasil Kromatografi Lapis Tipis (KLT). KA: Kering Angin, SM: Sinar Matahari

\section{Penetapan kadar fenolik total}

Penetapan kadar fenolik total menggunakan metode Folin Ciocalteau. Metode ini berdasarkan pada kekuatan mereduksi dari gugus hidroksi fenolik. Reagen Folin Ciocalteau diperoleh dari natrium tungstat dan natrium molibdat untuk menghasilkan senyawa molibdotungstat yang berwarna kuning (Prior dkk, 2005). Larutan $\mathrm{Na}_{2} \mathrm{CO}_{3} 7,5 \%$ biasa digunakan dalam reaksi untuk menghasilkan kondisi basa. Selama reaksi berlangsung gugus hidroksil pada senyawa fenolik bereaksi dengan reagen membentuk kompleks berwarna biru yang dihasilkan setara dengan konsentrasi ion fenolat, sehingga semakin besar konsentrasi senyawa fenolik semakin banyak ion fenol yang terbentuk, demikian pula dengan warna biru yang dihasilkan semakin pekat (Aspari \& Susanti, 2011).

Salah satu golongan fenol alami adalah asam galat dan pada pengujian ini asam galat digunakan sebagai larutan standar. Panjang gelombang maksimal yang didapatkan yaitu $759 \mathrm{~nm}$. Hasil absorbansi stabil didapatkan pada waktu 126 menit.

Persamaan regresi linier standar asam galat yaitu $\mathrm{y}=0,0080 \mathrm{x} \pm 0,0011$ dengan nilai koefisien $r$ sebesar 0,9998 . Persamaan kurva kalibrasi tersebut digunakan sebagai pembanding untuk menentukan konsentrasi senyawa fenolik total pada ekstrak daun cincau hijau. Kandungan total fenol pada ekstrak daun cincau hijau dinyatakan sebagai GAE (Gallic acid equivalent) dalam $\mathrm{mgGAE} / \mathrm{g}$.

Hasil nilai rata-rata kadar fenolik (Gambar 2) yang didapatkan pada ekstrak dengan perbedaan cara pengeringan simplisia kering angin, sinar matahari dan oven secara berturut-turut yaitu $32,7089 \pm 0,19 \mathrm{mgGAE} / \mathrm{g}, \quad 46,2500 \pm 0,34$ $\mathrm{mgGAE} / \mathrm{g}$ dan $59,5500 \pm 0,41 \mathrm{mgGAE} / \mathrm{g}$. Nilai kadar fenolik tertinggi yang dihasilkan yaitu pada ekstrak dengan cara pengeringan simplisia oven dibandingkan dengan sinar matahari dan kering angin. Pengaruh metode pengeringan terhadap total fenol juga dilaporkan oleh Bernard dkk (2014), bahwa total fenol yang dihasilkan melalui metode pengeringan dengan oven lebih tinggi dibandingkan dengan pengeringan dengan sinar matahari dan dikeringanginkan. Hal ini dapat disebabkan oleh inaktivasi enzim yang berlangsung lebih cepat. Bennett dkk (2011) melaporkan bahwa fenolik rentan terhadap degradasi oksidatif oleh polifenol oksidase selama pengeringan yang mengakibatkan reaksi kondensasi intermolekul dan kadarnya menurun. Pengeringan dengan oven menggunakan suhu yang lebih tinggi dari pengeringan 
dengan sinar matahari dan kering angin serta dalam waktu yang lebih singkat akan mempercepat proses inaktivasi enzim polifenol oksidase sehingga kadar total fenolik menjadi lebih tinggi (Bernard dkk, 2014). Jadi kadar fenolik berpengaruh pada suhu dan waktu pengeringan simplisia. Pengeringan simplisia dengan menggunakan kering angin yaitu dengan suhu ruang dan dalam waktu 10 hari pada suhu ruang sekitar $15-30^{\circ} \mathrm{C}$. Pengeringan menggunakan sinar matahari dalam waktu 5 hari pada suhu sekitar $30-35^{\circ} \mathrm{C}$, sedangkan pengeringan menggunakan oven pada suhu $50^{\circ} \mathrm{C}$ dalam waktu 7 jam.

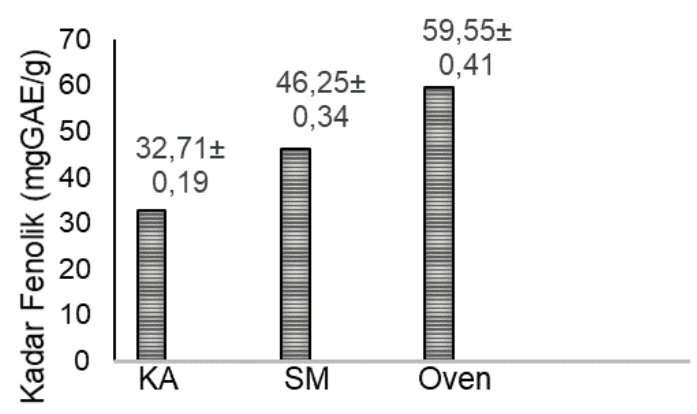

Jenis Ekstrak Berdasarkan Cara Pengeringan Simplisia

Gambar 2. Grafik Nilai Kadar Fenolik, KA: Kering Angin, SM: Sinar Matahari

\section{Uji tabir surya}

Penentuan nilai SPF untuk ekstrak dilakukan dengan mengukur absorbansi pada rentang panjang gelombang 290 $320 \mathrm{~nm}$, dengan interval $5 \mathrm{~nm}$. Kemudian dihitung dengan persamaan Mansur (1986).

Hasil uji tabir surya (Tabel 6 dan Gambar 3) yang didapatkan menunjukkan nilai rata-rata SPF dengan konsentrasi 50ppm, 100ppm, dan 150ppm pada masing-masing ekstrak dengan perbedaan cara pengeringan simplisia yaitu kering angin secara berurutan yaitu $2,4979 \pm 0,03$; $3,4113 \pm 0,03 ; 4,4787 \pm 0,01$ dengan sinar matahari $2,7379 \pm 0,0276 ; 3,4663 \pm 0,03$; $4,4824 \pm 0,03$ dan dengan oven $2,8777 \pm 0,03$ ; 3,9889 $\pm 0,03$; 5,2914 $\pm 0,04$. Adanya perbedaan bermakna antara kelompok ekstrak dengan cara pengeringan simplisia kering angin, sinar matahari, dan oven pada konsentrasi 50ppm, 100ppm dan $150 \mathrm{ppm}$, kecuali pada ekstrak dengan cara pengeringan simplisia kering angin dan sinar matahari pada konsentrasi 100ppm dan 150ppm.

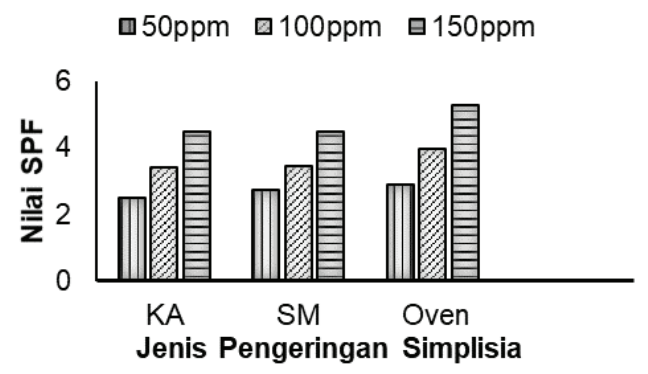

Gambar 3. Grafik Hasil Nilai SPF, KA: Kering Angin, SM: Sinar Matahari

Hasil nilai SPF terbesar diperoleh ekstrak dengan cara pengeringan simplisia menggunakan oven sedangkan yang paling terkecil yaitu ekstrak dengan cara pengeringan simplisia kering angin. Komponen bioaktif seperti fenol hidrokuinon, flavonoid, dan triterpenoid diduga memiliki potensi sebagai bahan krim tabir surya (Nurjanah dkk, 2015). Hasil tersebut berhubungan dengan nilai kadar fenolik yang didapat, dimana kadar fenolik ekstrak dengan cara pengeringan simplisia oven lebih tinggi dibandingkan dengan sinar matahari dan kering angin.

Menurut Wolf dkk (2001) senyawa fenolik khususnya golongan flavonoid mempunyai potensi sebagai tabir surya karena adanya gugus kromofor yang mampu menyerap sinar ultraviolet sehingga mengurangi intensitasnya pada kulit. Senyawa fenolik memiliki ikatan rangkap terkonjugasi di dalam inti benzen yang akan mengalami resonansi karena adanya transfer elektron ketika terpapar sinar UV. Mekanisme kerja perlindungan tabir surya dapat dijelaskan sebagai molekul senyawa yang menyerap energi dari sinar UV akan tereksitasi ke tingkat energi yang lebih tinggi, ketika kembali ke tingkat energi yang lebih rendah, akan 
melepaskan energi. Sementara itu, sinar UV yang diserap oleh molekul yang berpotensi sebagai tabir surya, akan memiliki energi yang lebih rendah, sehingga dapat mengurangi dampak negatif paparan sinar UV. Dengan mekanisme ini, senyawa fenol dan senyawa yang bersifat sebagai tabir surya berpotensi sebagai fotoproteksi (Yuliawati dkk, 2019).

Berdasarkan tipe proteksi SPF, sampel ekstrak dengan perbedaan cara pengeringan simplisia antara kering angin, sinar matahari dan oven memiliki tipe proteksi yang sama pada konsentrasi 50ppm, 100ppm, dan 150ppm secara berturut-turut yaitu minimal, minimal dan sedang. Proteksi minimal atau dengan nilai SPF 2-4 menunjukkan bahwa ekstrak dapat tahan atau melindungi kulit terhadap sinar matahari dua kali lebih lama tanpa kulit terbakar sedangkan proteksi sedang atau dengan nilai SPF 4-6 menunjukkan bahwa ekstrak dapat tahan atau melindungi kulit terhadap sinar matahari empat kali lebih lama tanpa kulit terbakar (Wilkinson, 1982). Semakin tinggi nilai SPF yang didapat pada suatu bahan maka semakin tinggi juga efektifitasnya untuk mencegah efek buruk dari sinar matahari (Dutra dkk, 2004). Menurut Badan Standarisasi Nasional (1996), syarat nilai faktor perlindungan tabir surya yaitu minimal 4 . Nilai SPF yang masuk ke dalam kategori tersebut yaitu ekstrak dengan cara pengeringan simplisia kering angin, sinar matahari dan oven pada konsentrasi 150 ppm.

\section{KESIMPULAN}

Hasil penelitian yang diperoleh dapat disimpulkan bahwa cara pengeringan simplisia dapat mempengaruhi nilai kadar fenolik. Nilai kadar fenolik yang diperoleh dapat berpengaruh terhadap nilai SPF.

\section{DAFTAR PUSTAKA}

Afaq, F., \& Mukhtar, H. 2001. Effects of solar radiation on cutaneous detoxification pathways. Journal of Photochemistry and Photobiology B: Biology, 63(1-3), 61-69.

Aspari, P., D., Susanti, H. 2011. Perbandingan Kadar Fenolik Total Ekstrak Metanol Kelopak Merah dan Ungu Bunga Rosella (Hibiscus sabdariffa Linn) secara Spekrpfotometri. Jurnal Prosiding Seminar Nasional Home Care. 7378.

Badan Standarisasi Nasional. 1996. Sediaan Tabir Surya, SNI 16 4399 - 1996. Jakarta: Dewan Standarisasi Nasional, 1.

Bennett, L.E., Jegasothy, H., Konczak, I., Frank, D., Sudharmarajan, S., Clingeleffer, P.R. 2011. Total polyphenolics and anti-oxidant properties of selected dried fruits and relationships to drying conditions. Journal of Functional Foods 3(2):115- 124.

Bernard, D., Kwabena, A.I., Osei, O.D., Daniel, G.A., Elom, S.A., Sandra, A. 2014. The effect of different drying methods on the phytochemicals and radical scavenging activity of Ceylon Cinnamon (Cinnamomum zeylanicum) plant parts. European Journal of Medicinal Plants 4(11):1324-1335.

Cefali, L. C., Ataide, J. A., Moriel, P., Foglio, M. A., \& Mazzola, P. G. 2016. Plant-based active photoprotectants for sunscreens. International Journal of Cosmetic Science, 38(4), 346-353.

Depkes. 1989. Materia Medika Indonesia. Departemen Kesehatan Republik Indonesia, 172-176.

Farida, Y., Gangga, E., Kartiningsih, Elisa, \& Teguh. 2015. Characteristic of $70 \%$ Ethanol Extract from Cyclea 
barbata Miers leaves and Antioxidant Activity using DPPH Method. Proceedings of The 9th Joint Conference on Chemistry, The 9th Joint Conferences on Chemistry, 369-376.

Hernani. 2005. Tanaman Berkhasiat Antioksidan. Jakarta: Swaday, 1620.

Kate, D. I. 2014. Penetapan Kandungan Fenolik Total dan Uji Aktivitas Antioksidan dengan Metode DPPH Ekstrak Metanolik Umbi Bidari Upas (Merremia mamnosa (Lour) Hallier f.). Skripsi. Fakultas Farmasi. Universitas Sanata Dharma, 2.

Kemenkes. 2017. Farmakope Herbal Indonesia. Jakarta: Kementrian Kesehatan Republik Indonesia, 528-531.

Mahadi, R., Rasyiid, M., Dharma, K. S., Anggraini, L., Nurdiyanti, R., \& Nuringtyas, T. R. 2018. Immunomodulatory and Antioxidant Activity of Green Grass Jelly Leaf Extract (Cyclea barbata Miers.) In Vitro. Journal of Tropical Biodiversity and Biotechnology, 3(3), 73.

Manoi, F. 2015. Pengaruh Cara Pengeringan Terhadap Mutu Simplisia Sambiloto. Buletin Penelitian Tanaman Rempah Dan Obat, 17(1), 1-5.

Mansur, J. E. 1986. Determination Of Sun Protection Factor For Spectrophotometry. An. Bras. Dermatol, 121-124.

Muller, J. 2006. Drying Of Medical Plants In R.J. Bogers, L.E.Cracer, And D Lange. Medical and Aromatic Plant, Spinger, The Netherland, 237-252.

Nurjanah, Nurilmala, N., Anwar, E., Luthfiyana, N., 2015. Identification of bioactive compounds seaweed as raw sunscreen cream. The 2nd International Symposium on
Aquatic Products Processing and Health [ISAPROSH].

Prior, R. L., Wu, X., \& Schaich, K. 2005. Standardized methods for the determination of antioxidant capacity and phenolics in foods and dietary supplements. Journal of Agricultural and Food Chemistry, 53(10), 4290-4302.

Priyanka, S., Inala, M. S. R., Nandini, H., Kutty, A., \& Kiranmayee, P. 2018. A pilot study on sun protection factor of plant extracts: An observational study. Asian Journal of Pharmaceutical and Clinical Research, 11(4), 67-71.

Sayre, R. E. 1979. a Comparison of I N V I $\mathrm{V} O$ and I N Vitro Testing of Sunscreening Formulas. Photocem. Photobiol 29, 559.566.

Setiawan, T. 2010. Uji Stabilitas Fisik Dan Penentuan Nilai SPF Krim Tabir Surya Yang Mengandung Ekstrak Daun Teh Hijau (Camellia sinensis L.), Oktil Metoksisinamat, Dan Titanium Dioksida. Skripsi. FMIPA. UI. 1-2, 108.

Siddiqui, N., Rauf, A., Latif, A., \& Mahmood, $\quad$ Z. 2017. Spectrophotometric determination of the total phenolic content, spectral and fluorescence study of the herbal Unani drug Gul-e-Zoofa (Nepeta bracteata Benth). Journal of Taibah University Medical Sciences, 12(4), 360-363.

Suhartono, E. 2002. Oxygen Toxicity by Radiation if Effect of Glutamic Piruvat Transaminase (GPT) Activity Rat Plasma After Vitamin C Treatment. In. Environmental Chemistry and Toxicology, 97.

Wilkinson, J. B. 1982. Harry's Cosmeticology. New York: Chemical Publishing Company Inc, 240-241.

Wolf, R., Wolf, D., Morganti, P., Ruocco, V.. 2001. Sunscreens. J. Clinic. Dermatol. 19: 452- 459. 
Yuliawati, K. M., Sadiyah, E. R., Solehati,

R., \& Elgiawan, A. 2019.

Pengujian Aktivitas Tabir Surya

Ekstrak dan Fraksi Daun Kopi

Robusta ( Coffea canephora ).

Indonesian Journal of

Pharmaceutical Science and

Technology. 1(1). 24-29. 